\title{
SEISMIC BEHAVIOUR OF THE BEAM-TO-COLUMN DOWEL CONNECTIONS: MACRO MODELLING
}

\author{
Matej Fischinger ${ }^{1}$, Blaz Zoubek ${ }^{2}$, Tatjana Isakovic ${ }^{3}$ \\ ${ }^{1}$ University of Ljubljana, Faculty of Civil and Geodetic Engineering \\ Jamova 2, 1000 Ljubljana, Slovenia \\ e-mail: matej.fischinger @ fgg.uni-lj.si \\ ${ }^{2,3}$ University of Ljubljana, Faculty of Civil and Geodetic Engineering \\ Jamova 2, 1000 Ljubljana, Slovenia \\ \{blaz.zoubek, tatjana.isakovic\}@fgg.uni-lj.si
}

Keywords: Seismic behavior, precast industrial buildings, dowel connection, macro model

\begin{abstract}
Since the knowledge about the response of dowel connections was quite limited, the adequate numerical models were almost not available. Using the results of experiments, performed within the SAFECAST, the numerical models for monotonic as well as cyclic response of dowel connections were defined. Firstly the detailed FEM modeling has been performed in order to identify the important parameters influencing the response. Based on these analyses the results of the experiments were generalized (for more details see the accompanying paper [2]). After that, quite robust hysteretic macro-model [10], which can be used for monotonic as well as dynamic analyses of dowel connections, was defined. First the procedure that can be used to define the input parameters, based on the material data and construction details of the dowel connection, will be proposed. The adequacy of the procedure will then be tested by comparing the analytical and experimental results.
\end{abstract}




\section{INTRODUCTION}

Precast buildings have been frequently used in many European countries. Predominant type of these structures consists of an assemblage of columns tied together with beams. Among many types of different connections between precast elements, the connection using steel dowel is the most common. Nevertheless, the quantified knowledge of their inelastic response to earthquakes has been poor. This is partly due to the fact that the predominant mechanisms of the seismic response of the connections are complex and difficult to model. In practice connections are predominantly designed by engineering feeling and numerical verifications are seldom done. The cyclic behaviour of the dowel connections was systematically experimentally tested on the series of full-scale models in the frame of the European project SAFECAST [1, 2]. The main European associations of the precast manufacturers and different research institutions (including the University of Ljubljana) from the most earthquake prone areas in Europe, joint their efforts to define the design procedures for different types of connections in precast buildings. The supporting experimental campaign has been without comparison in the past. A large number of different connections (traditional, innovative, dissipative, connecting different structural elements) and structural assemblages in large scale have been tested. Monotonic, cyclic, PSD and shake table tests were performed. The results from these experiments and findings of FE analysis performed with ABAQUS [2] helped to define appropriate macro models. These models are much less complex and time consuming than FE models and therefore allow for parametric and probabilistic studies. They are essential for satisfactory modeling of the global response of the precast structures.

\section{ANALYTICAL INVESTIGATION OF THE RESPONSE}

In the past, some research on the dowel mechanism has been already done [3-5]. However, the knowledge about the whole response envelope under monotonic and cyclic loading remains quite poor. In this section, analytical investigation of the force - displacement relationship is presented (Fig. 1) and the procedure for the input parameters for hysteretic macromodels is proposed. First three characteristic points of the monotonic response will be defined based on the experimental and FEA results [2] (Fig. 1) - 1.) yielding of the dowel and crushing of the concrete; 2.) midpoint; 3.) maximal resistance. After that, cyclic degradation will be evaluated.
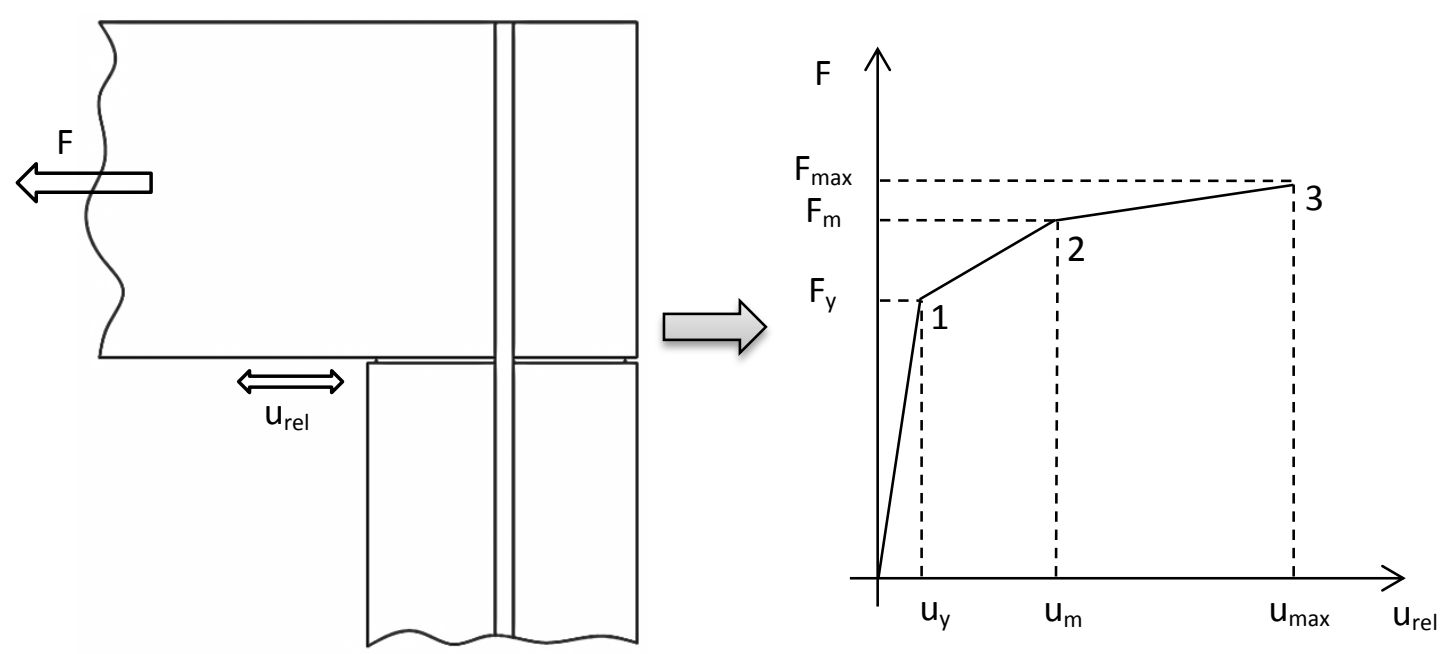

Figure 1: Schematic presentation of the force-displacement response of the dowel connection. 


\subsection{YIELDING OF STEEL DOWEL AND CRUSHING OF CONCRETE}

At certain level of loading a plastic hinge is formed in the dowel at some depth in the column (Fig. 2). The concrete in front of the dowel starts to crush. For that reason larger deformations (rotations) of the dowel are allowed.

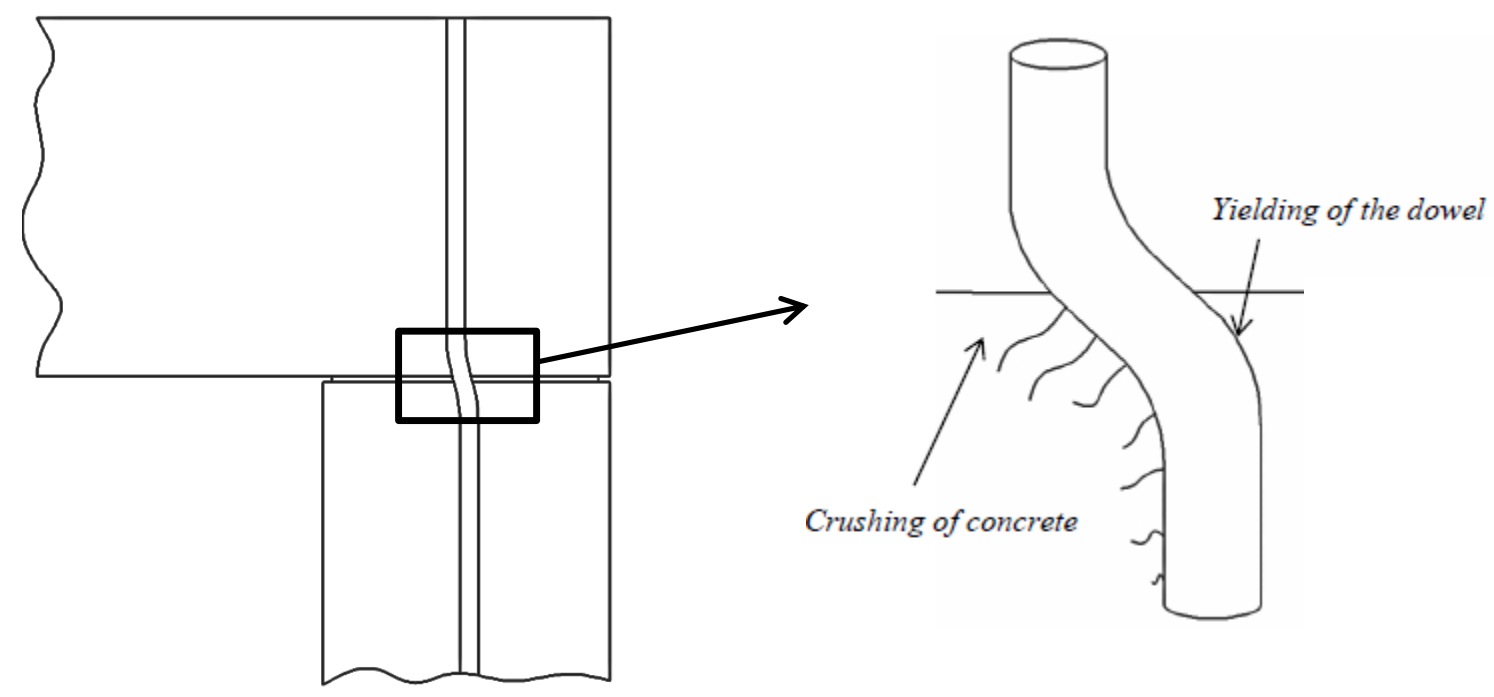

Figure 2: Yielding of the steel dowel and crushing of the surrounding concrete.

At the moment right before the plastification in the dowel starts, the stress state in the concrete in front of the dowel is as presented in Fig. 3. The figure shows the results of finite element analysis and the simplification which will be later used for the calculation of the first characteristic point of the monotonic response envelope. It is assumed that up to this point the behavior of the concrete remains elastic. Therefore the usage of the theory of the beam on the elastic foundation is appropriate. If this is the case, the depth of the intercept can be estimated at $L=2.5 d_{d}$, where $d_{d}$ is the diameter of the dowel [5] (Fig. 3).

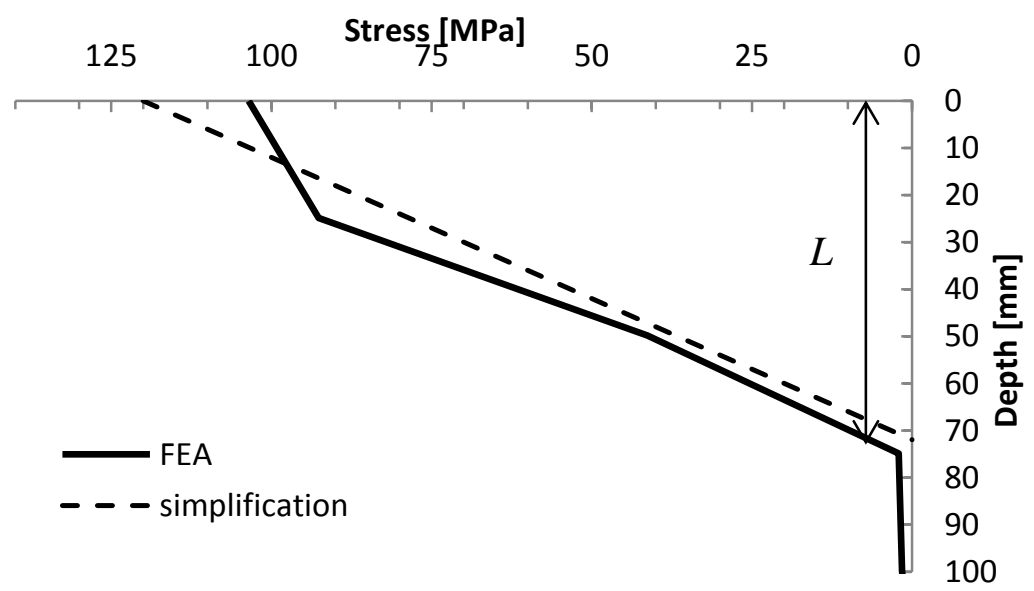

Figure 3: Compressive stresses in front of the dowel obtained from the FE analysis and the simplification of the stress-path at the start of yielding

FEM analysis [2] and previous studies [4, 5] indicate that due to the confining effects the maximal compression stresses reached in the concrete are much higher than its uniaxial compression strength (1). 


$$
f_{c c}^{*}=k_{\text {conf }} f_{c c}
$$

In the equation (1), $f_{c c}$ is the uniaxial compressive strength of concrete, $f_{c c}{ }^{*}$ the maximal compressive strength of concrete under confining effects and $k_{\text {conf }}$ the factor of confinement. Vintzeleou and Tassios [5] suggest value of 5 for $k_{\text {conf }}$. The results of the FE analysis presented in the accompanying paper [2] reveal much lower values $-k_{\text {conf }} \approx 2$. In Fig. 4 principal stresses in front of the dowel obtained from the analysis are shown. It can be seen that the second and the third principal stresses are approximately $1 / 3$ of the first principal stresses (the compressive stresses in the direction of loading). In this case, according to different studies [6], the maximal compressive strength of concrete ranges from 2 to 3 the uniaxial compressive strength which confirms the findings of the FE analysis.

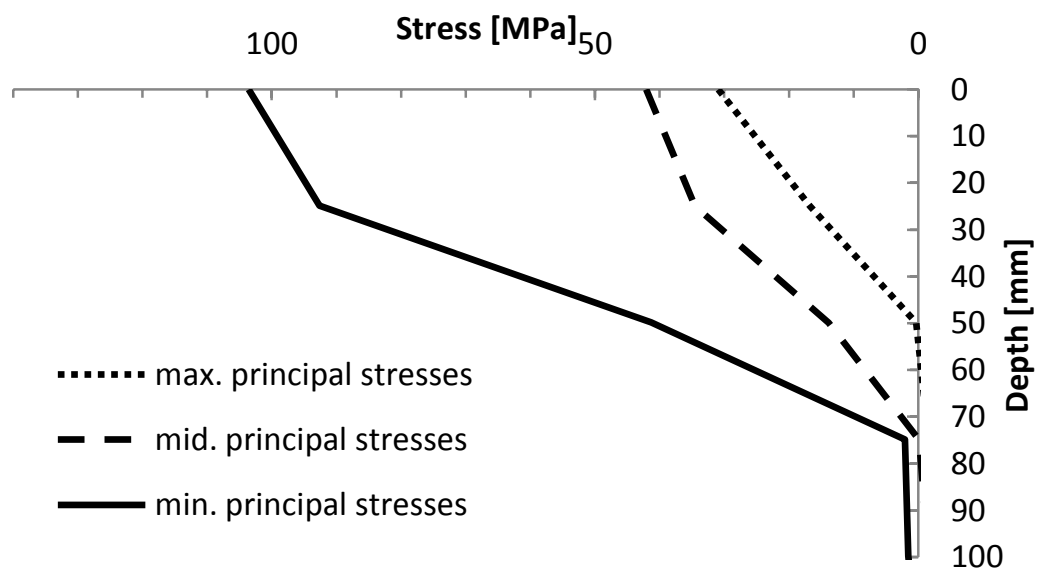

Figure 4: Principal stresses in the concrete in front of the dowel

Now it is possible to calculate the force in the connection at the moment of yielding of the dowel by simply integrating the stresses under the dowel (2).

$$
F_{y}=k_{\text {conf }} f_{c c} d_{d}\left(8 \cdot 0.314 d_{d}\right) / 2
$$

The relative displacement is calculated using the theory of the beam on the elastic foundations $[7,8]$ :

Where:

$$
u_{y, r e l}=2 F_{y}(1-\beta e) /\left(2 \beta^{3} E_{s} I\right)
$$

$\beta=(K d / 4 E I)^{1 / 4}[8]$ and

$K=269 f_{c c}{ }^{\prime 0.5} / d_{d}{ }^{2 / 3}[9]$

$e$...eccentricity (half of the thickness of the neoprene bearing pad)

$I=\frac{\pi d_{d}^{4}}{64} \ldots$ moment of inertia of the dowel section

$E_{S} \ldots$...lastic modulus of the steel used for the dowel

\subsection{MAXIMAL RESISTANCE}

When the connection fails, the maximum flexural resistance of the dowel is reached. The analytical stress-path in the concrete in front of the dowel with the simplification is presented in Fig. 5. 


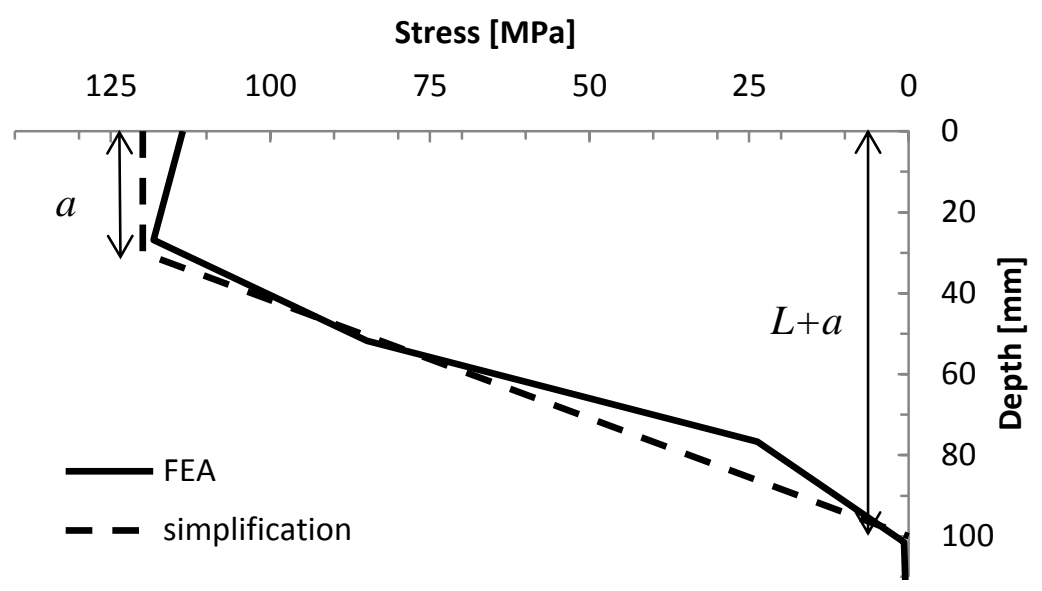

Figure 5: Compressive stresses in front of the dowel obtained from the FE analysis and the simplification of the stress-path when the maximal resistance is reached

Fig. 5 shows that the stresses are approximately constant up to the depth of the plastic hinge $a$. $a$ can be easily determined from the equilibrium in Fig. 6 (4).

$$
a=\sqrt{2 M_{p l} / k_{\text {conf }} f_{c c} d_{d}}
$$

$M_{p l}$ (please see equation (4) and Fig. 6) is the flexural strength of the steel dowel which can be calculated with the following expression (5):

$$
M_{p l}=k_{h, a} W_{p l} f_{y}
$$

$\mathrm{k}_{\mathrm{h}, \mathrm{a}}$ is the factor of hardening of steel and reduction in strength due to the axial forces in the dowel (6). $W_{p l}$ is the plastic section modulus of the dowel section.

$$
\begin{gathered}
k_{h, a}=f_{u} / f_{y}\left(1-\alpha^{2}\right) \\
\alpha=\sigma_{s, N} / f_{y} \\
\sigma_{s, N}=N / A_{d},
\end{gathered}
$$

where $N$ is the axial force in the dowel, $A_{d}$ is the area of the dowel section, $f_{y}$ is the yield strength and $f_{u}$ is the maximal strength of the steel used for the dowel.

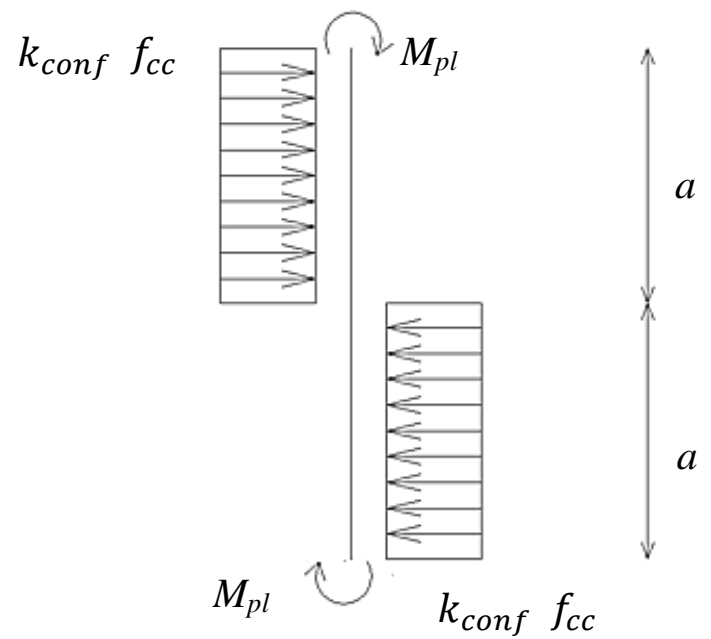

Figure 6: The equilibrium from which the depth of the plastic hinge can be determined. 
Under the plastic hinge, the compressive stresses linearly decrease up to the depth of the intercept, which can be estimated at $L+a$ (Fig. 5). In short, from the top surface to the depth of the plastic hinge a nonlinear behavior of concrete is assumed. Under the plastic hinge, the concrete remains elastic, therefore the dowel behaves as a beam on the elastic foundations.

The strength of the connection can now be simply calculated by integrating the compressive stresses in front of the dowel (Fig. 5):

$$
F_{\text {max }}=k_{\text {conf }} f_{c c} d_{d}\left(a+\left(2.5 d_{d}-a\right) / 2\right)
$$

Relative displacement at maximal resistance $u_{\max }$ is determined from the equation (9). It is assumed that the rotation of the dowel arises mainly from the rotation in the plastic hinge. Based on the result of the FE analysis it is assumed that the length of the plastic hinge is approximately $2 d_{d}$ (Fig. 7).

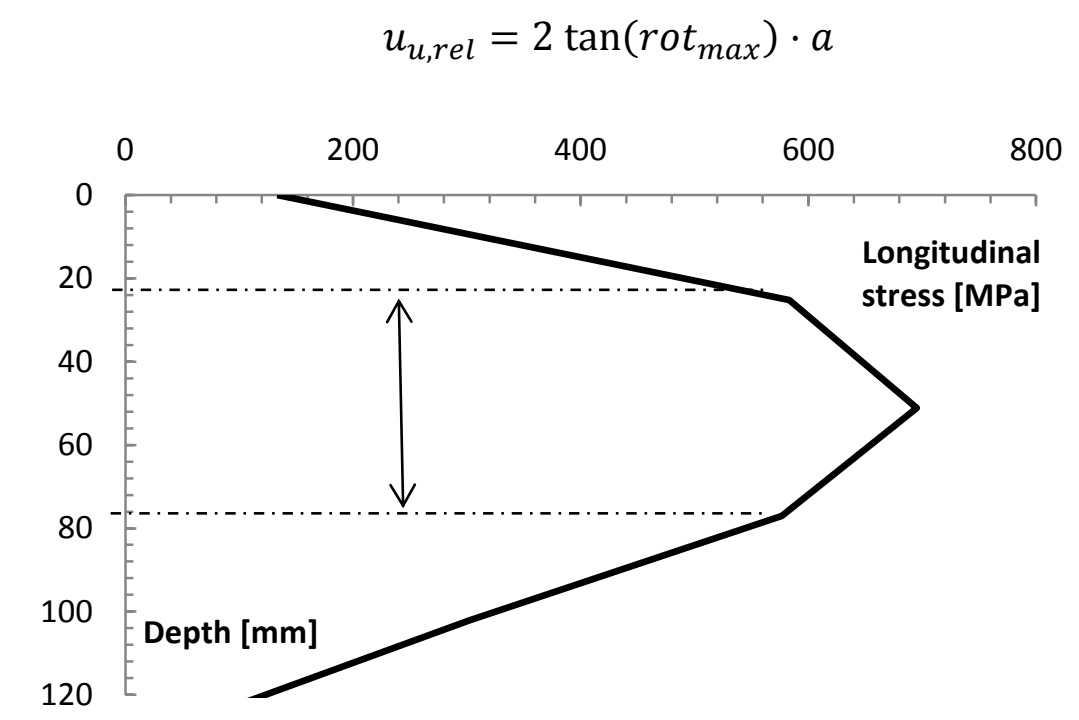

Figure 7: Longitudinal stresses in the dowel - the length of the plastic hinge is approximately $2 d_{d}$

\subsection{MIDPOINT} force

To capture the response more accurately, another characteristic point was defined at the

$$
F_{m}=\left(F_{y}+F_{\text {max }}\right) / 2
$$

The relative displacement at this force can be determined using a formula suggested by Vintzeleou and Tassios [5]:

$$
u_{i, r e l}=1.15 u_{y} u_{\max }\left(\left(F_{m} / F_{\max }\right)^{4}-0.5\left(F_{m} / F_{\max }\right)^{3}\right.
$$

\subsection{CONTRIBUTION OF THE NEOPRENE BEARING PAD}

To take into account the additional resistance of the neoprene bearing pad, its stiffness should first be calculated (12).

$$
k_{e}=G_{n} A_{e f f} / t_{n}
$$

$G_{n}$ is the shear modulus of the elastomer (neoprene), $t_{n}$ is the thickness of the neoprene bearing pad and $A_{e f f}$ is the compressed area of the pad. The force in the neoprene pad is then 
simply calculated with the equation (13). It is assumed that the neoprene bearing pad behaves elastically.

$$
F_{\text {neo }}\left(u_{r e l}\right)=k_{e} u_{\text {rel }}
$$

The total response of the connection is then obtained by adding the contribution of the pad to the forces calculated under 2.1, 2.2, 2.3, 2.4 (Fig. 8).

In the experiment and FE analysis a quite large contribution of the neoprene bearing pad was observed when monotonic loading was applied [2]. In the case of cyclic response, the influence of the pad was much smaller due to smaller relative displacements (and rotations) between the beam and column [2]. For this reason the contribution of the neoprene bearing could be neglected if modeling cyclic response of the connection.

\subsection{CYCLIC DEGRADATION}

Due to cyclic degradation of concrete and steel the resistance of the connection in the case of cyclic loading is much lower. Maximal resistance of the connection is therefore reduced by the factor $k_{c y c}(14)$.

$$
k_{c y c}=1-\frac{1}{7} \sqrt{n-1} \quad[5]
$$

In the equation (14) $\mathrm{n}$ is the number of cycles at constant amplitude. The maximal force in the connection is then determined with the following expression (14):

$$
F_{\max , c y c}=k_{c y c} F_{\max }
$$

\section{APPLICATION OF THE PROPOSED PROCEDURE}

The results of the experiments performed at the University of Ljubljana in the frame of the SAFECAST project $[1,2]$ were used to test the procedure proposed in the previous chapter. The procedure was used for the determination of the input data for the hysteretic model included in the Opensees software [10].

The material data and the construction details of the investigated dowel connection are given in Table 1. The input data for the hysteretic model are given in Tables 2 and 3.

\begin{tabular}{ll}
\hline variable & \\
\hline$f_{c c}$ & $60 \mathrm{MPa}$ \\
$k_{\text {conf }}$ & 2 \\
$f_{y}$ & $580 \mathrm{MPa}$ \\
$f_{u}$ & $700 \mathrm{MPa}$ \\
$E_{s}$ & $200000 \mathrm{MPa}$ \\
$d_{d}$ & $28 \mathrm{~mm}$ \\
$\alpha$ & 0.09 \\
$G_{n}$ & $1 \mathrm{MPa}$ \\
$A_{e f f}$ & $24200 \mathrm{~mm}^{2}$ \\
$t_{n}$ & $10 \mathrm{~mm}$
\end{tabular}

Table 1: The data about the materials and construction details

According to the finite element analysis, values of 2 for $k_{\text {conf }}$ and 0.09 for $\alpha$ were taken. If there are no FEA results available, the values should be chosen reasonably by the user. 


\begin{tabular}{lll}
\hline Char. point & $F[\mathrm{kN}]$ & $u[\mathrm{~mm}]$ \\
\hline 1 & 121 & 1.5 \\
2 & 168 & 9 \\
3 & 241 & 30 \\
\hline
\end{tabular}

Table 2: The input data for the hysteretic model in Opensees [10] - monotonic response

\begin{tabular}{lll}
\hline Char. point & $F[\mathrm{kN}]$ & $u[\mathrm{~mm}]$ \\
\hline 1 & 118 & 1.5 \\
2 & 150 & 9 \\
3 & 150 & 30 \\
\hline Parameter & & \\
\hline pinchX & 0.67 & \\
\hline pinchY & 0.5 & \\
\hline damage1 & 0.0 \\
\hline damage2 & 0.035 & \\
\hline
\end{tabular}

Table 3: The input data for the hysteretic model in Opensees [10] - cyclic response

The selection of the parameters pinchX, pinchY, damage1 and damage 2 was based on the experimental results (Table 3). The contribution of the neoprene pad was neglected in the case of the macro-model used for cyclic loading.

\section{RESULTS}

The comparison between the experimental and analytical results is presented in Fig. 8 and 9. The match between the experiment and the analysis is quite good for the monotonic and cyclic loading. Not only the force-displacement relationship, but also the dissipated energy is more or less similar (Fig. 9).

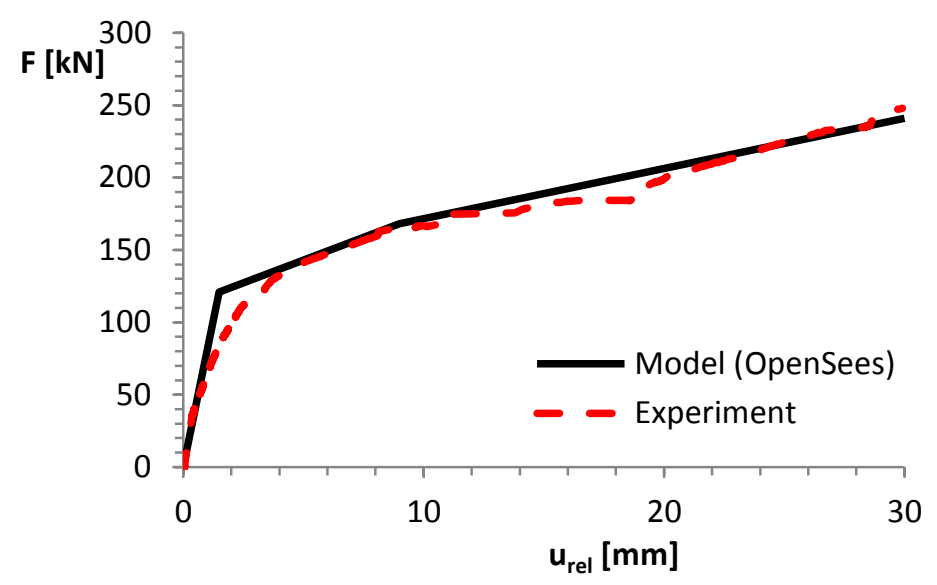

Figure 8: Comparison between the experimental and analytical results - a) force-displacement relationship and (b) dissipated energy. 
a)
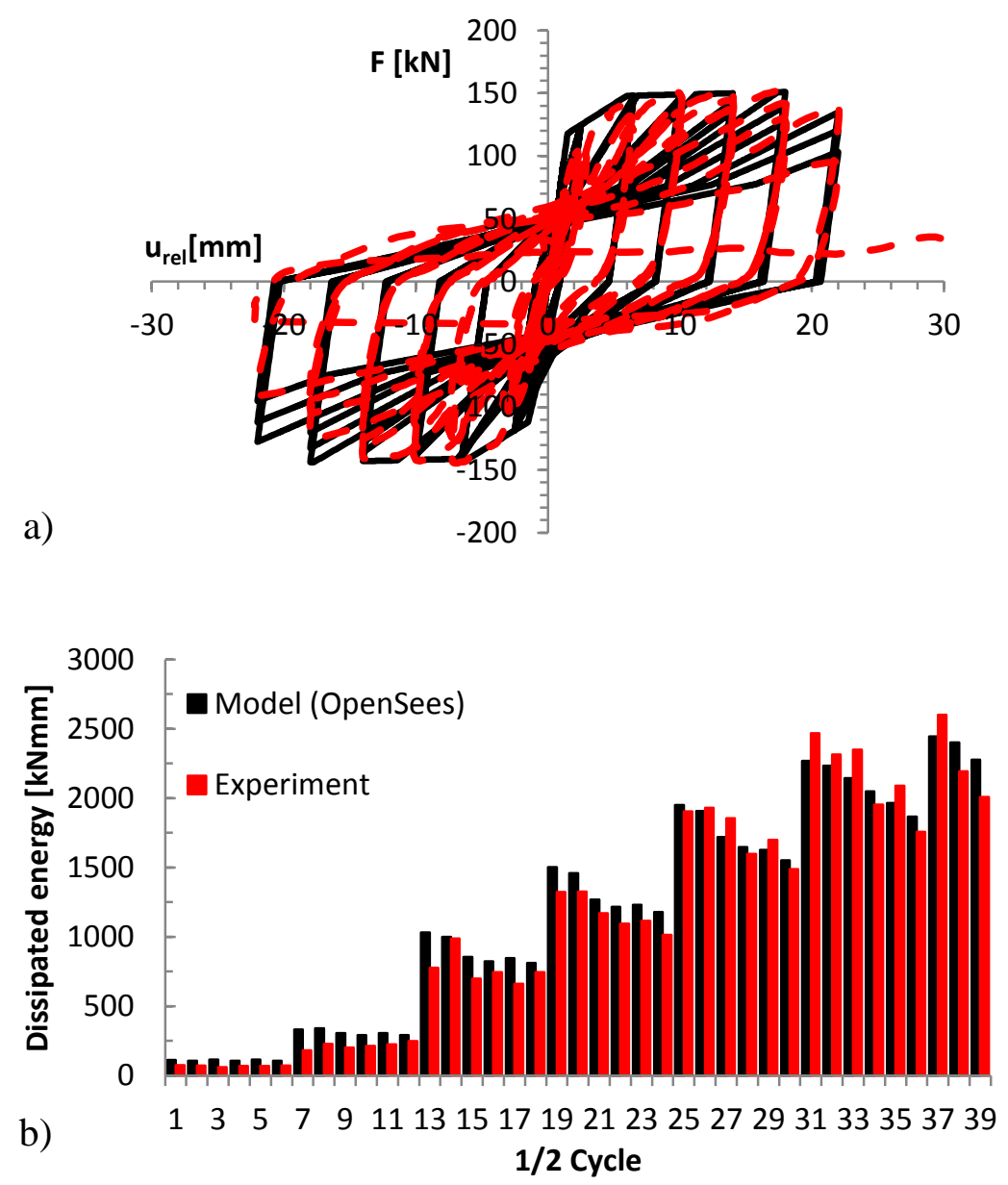

Figure 9: Comparison between the experimental and analytical results - a) force-displacement relationship and (b) dissipated energy.

\section{CONCLUSION}

The paper represents macro-modeling of the typical beam-to-column dowel connection used in precast industrial buildings. With the support of the experiments and finite element analysis a simple procedure for the determination of the input parameters for the hysteretic macro-model included in the Opensees software [10] was proposed. The model gives promising results for monotonic and cyclic loading. Too sophisticated FE models did not allow for some extended parametric and probabilistic studies of the precast industrial buildings due to their computational inefficiency. However, with the here presented macro-models this is feasible.

\section{ACKNOWLEDGEMENTS}

The presented research was supported by the SAFECAST project "Performance of Innovative Mechanical Connections in Precast Building Structures under Seismic Conditions" (Grant agreement no. 218417-2) in the framework of the Seventh Framework Programme (FP7) of the European Commission. Experiments were completed at the Slovenian National Building and Civil Engineering Institute (ZAG). The specimens were constructed at Primorje d.d. company. 


\section{REFERENCES}

[1] SAFECAST Performance of Innovative Mechanical Connections in Precast Building Structures under Seismic Conditions. http://www.safecastproject.eu/, 2012.

[2] B., Zoubek, M., Fischinger, T., Isakovic, Seismic Behaviour of the Beam-to-Column Dowel Connections: FEM Analysis, International Conference on Computational Dynamics and Earthquake Engineering -COMPDYN 2013

[3] H. Dulascka, Dowel Action of reinforcement crossing cracks in concrete. J. ACI, 69-70: 754-757, 1972.

[4] E.N. Vintzeleou, T.P. Tassios, Behaviour of Dowels under Cyclic Deformations, ACI Struct. J., 84(1): 18-30, 1987.

[5] E.N. Vintzeleou, T.P. Tassios, Mathematical model for dowel action under monotonic and cyclic conditions, Mag. Concr. Res., 38: 13-22, 1986.

[6] A.H. Gandomi, S.K. Babanajad, A.H.Alavi, Y. Farnam, Novel Apporach to Strength Modeling of Concrete under Triaxial Compression, J. Mater. Civ. Eng., 24(9): 11321143, 2012.

[7] B.F. Friberg, Design of dowels in transverse joints of concrete pavements. American Society of Civil Engineers, Proceedings, 64(2): 1809-1828, 1938.

[8] S. Timoshenko, Strength of materials, Part II, advanced theory and problems. American Society of Civil Engineers, Proceedings, Third ed. Princeton, NJ: Van Nostrand; 1956.

[9] S. Dei Poli, S. M. Di Prisco, P.G. Gambarova, Shear Response, Deformations and Subgrade Stiffness of a Dowel Bard Embedded in Concrete, ACI Struct. J., 89(6): 665-675, 1992.

[10] S. Mazzoni, F. Mckenna, M.H. Scott, G.L. Fenves, B. Jeremic. Open System for Earthquake Engineering Simulation (OpenSees) - Command Language Manual, UCB, PEER, Berkeley, http://opensees.berkeley.edu/, 2009. 